\title{
PENGARUH LITERASI KEUANGAN TERHADAP INKLUSI KEUANGAN DENGAN MENGGUNAKAN SOCIAL CAPITAL SEBAGAI VARIABEL MEDIATOR
}

\author{
Maya Angela Natalia ${ }^{1}$ \\ Management Department, Universitas Multimedia Nusantara, Indonesia \\ maya041297@gmail.com
}

Florentina Kurniasari $\mathbf{T}^{2}$

Technology Management Department, Universitas Multimedia Nusantara, Indonesia florentina@umn.ac.id

\section{Ernie Hendrawaty ${ }^{3}$}

Faculty of Economics and Business, Universitas Negeri Lampung, Indonesia ernie.hendrawaty@unila.ac.id

\section{Vina Medya Oktaviani ${ }^{4}$}

Technology Management Department, Universitas Multimedia Nusantara, Indonesia vina.medya@student.umn.ac.id

Diterima 24 Maret 2020

Disetujui 20 April 2020

\begin{abstract}
MSMEs plays an important role to support Indonesia's economic growth. There is an urgency to increase the financial literacy and skills for MSMEs, especially in managing their fund to make their businesses alive. The government believed that the financial literacy was one way to achieve the society prosperity by taking advantage from the collectivisim culture of Indonesian. This study is to examine the effect of financial literacy on financial inclusion by using social capital mediation at MSMEs in South Tangerang City. The questionnaires were distributed to some MSME's district in South Tangerang regency. All data collection were furthered analyzed using Structural Equation Model on AMOS 24. The research showed that financial literacy does not affect financial inclusion, financial literacy affects social capital and social capital as a mediator variable on the relationship of financial literacy affects financial inclusion in MSMEs in South Tangerang City. It can be concluded that there is an influence of social capital that connects financial literacy to financial inclusion. All the stakeholders in the financial ecosystem in Indonesia, including financial institutions and the government as regulators, will be better to use the power of social capital to increase financial literacy and financial inclusion in Indonesia.
\end{abstract}

Keywords: Financial Literacy, Financial Inclusion, Social Capital, SMEs, South Tangerang City 


\section{PENDAHULUAN}

Sebagai upaya pemerintah dalam membangun negara Indonesia maka diperlukan tren pertumbuhan ekonomi yang menguat berdampak positif terhadap kesejahteraan masyarakat (Bappenas, 2019). Untuk mendapatkan kesejahteraan masyarakat yang semakin baik diperlukan adanya upaya dari pemerintahan untuk meningkatkan hal tersebut. Terdapat beberapa komponen-komponen pendukung untuk mendapatkan kesejahteraan masyarakat di Indonesia. Komponen yang dimaksud berupa pertumbuhan ekonomi, penanggulangan kemiskinan, pemerataan pendapatan dan stabilitas sistem keuangan. Dengan menggunakan instrument untuk kebijakan berupa literasi keuangan dan inklusi keuangan yang dilihat dari berbagai aspek seperti kondisi ekonomi, kondisi demografis, kondisi geografis dan kondisi budaya di Indonesia (Soetiono \& Setiawan, 2018).

Akses terhadap layanan produk dan jasa lembaga keuangan merupakan permasalahan yang kompleks sehingga harus menjadi fokus pemerintah untuk terus mengurangi permasalahan ini. Menurut survei dari OJK di tahun 2016 indeks literasi keuangan di Indonesia mengalami peningkatan dari tahun 2013 dari 21,8\% menjadi 29,7\% di tahun 2016. Angka ini berarti pada setiap 100 penduduk di Indonesia hanya sekitar 30 orang penduduk yang masuk ke dalam kategori well literate atau memiliki literasi keuangan yang baik. indeks literasi keuangan di Indonesia khusus di pulau Jawa sudah terliterasi dengan baik. Dengan perolehan untuk DKI Jakarta sebesar 40\% sampai Jawa Barat 33\%. Di sisi lain indeks literasi keuangan di Indonesia belum mencapai 50\% dimana belum tercapai setengah dari penduduk Indonesia yang memiliki pengetahuan yang cukup untuk dapat mengelola keuangannya dengan baik (OJK, 2019).

Sehingga keputusan para pelaku usaha untuk mengakses permodalan dari lembaga keuangan dan mengelola keuangan mereka dengan berbagai pihak terkait tentu saja menggambarkan bagaimana tingkat financial inclusion atau inklusi keuangan di definisikan sebagai keadaan di mana semua orang dewasa di usia kerja memiliki akses efektif ke kredit, tabungan, pembayaran, dan asuransi dari penyedia layanan formal. Data inklusi keuangan di Indonesia data menunjukkan tingkat inklusi keuangan di angka 67,8\% di tahun 2016 dimana naik sebesar 8,1\% dari survei terakhir di tahun 2013 yaitu sebesar 59,7\%. Hal ini berarti masyarakat Indonesia telah mengakses lembaga jasa keuangan formal.

Untuk mencapai tingkat inklusi keuangan yang baik seorang individu atau pelaku usaha harus melewati proses pengambilan keputusan untuk menggunakan sumber daya yang mereka miliki. Dengan adanya era globalisasi pengaruh modernisasi membawa perubahan sosial budaya di dalam masyarakat Indonesia dari tradisionalis menjadi lebih modern dan tercermin melalui pola pengelolaan keuangan masyarakat yang semakin maju serta memanfaatkan produk dan jasa keuangan dari lembaga keuangan formal (Soetiono \& Setiawan, 2018). Namun belum seluruh masyarakat Indonesia menerima modernisasi tersebut. Beberapa daerah di Indonesia masih menggunakan lembaga tradisional (non formal) untuk memfasilitasi kebutuhan keuangan masyarakat tersebut karena berdasarkan prinsip kepercayaan dan penghormatan atas adat yang cukup kuat dan membuat masyarakat Indonesia lebih nyaman untuk melakukan kegiatan keuangan melalui lembaga tradisional dibandingkan dengan lembaga keuangan formal (OJK,2015).

Salah satu kelompok sasaran SNLKI (Strategi Nasional Literasi Keuangan Indonesia) tahun 2017 adalah UMKM (Usaha Mikro, Kecil dan Menengah). UMKM memiliki peran penting dan strategis dalam pembangunan perkenomian di Indonesia dan 
berperan untuk menyerap tenaga kerja di Indonesia serta pendistribusian hasil-hasil pembangunan. Pada proses pengembangannya UMKM dapat difasilitasi oleh pasar keuangan, dan dapat menyebabkan pengurangan kemiskinan yang substansial yang akan mempengaruhi pertumbuhan perekonomian nasional (Kemendag, 2013).

Saat ini tingkat literasi untuk UMKM masih rendah yaitu sebesar 23,8\%. Salah satu hambatan UMKM tidak menggunakan instrument pembiayaan adalah mereka tidak menyadari atau kurang mendapatkan informasi untuk produk atau jasa pembiayaan diri mereka yang disediakan oleh lembaga keuangan (OECD,2015). Sedangkan tingkat inklusi keuangan di dalam pengusaha UMKM adalah sebesar 65,3\%. Di dalam survei Baseline Portfolio Investasi UMKM Rumah Tangga yang dilakukan oleh OJK pada tahun 2014 juga disebutkan ketika UMKM mengalami kesulitas keuangan di dalam usaha, sebanyak 26,4\% UMKM cenderung memilih untuk meminjam kepada keluarga, teman, atasan, tetangga, atau arisan. Dan hanya sebesar $7 \%$ yang memilih untuk melakukan pinjaman ke bank. Sehingga dapat disimpulkan bahwa responden cenderung memilih pembiayaan informal sebagai solusi dari kesulitan keuangan mereka.

Tangerang Selatan merupakan salah satu kota di provinsi Banten yang memberikan kontribusi pertumbuhan yang besar terhadap provinsi Banten, yang ditandai dengan angka pertumbuhan penduduk terbesar dengan tingkat upah rata-rata pekerja yang berada di atas kota/kabupaten lainnya serta memiliki Indeks Pembangunan Manusia (IPM) terbesar yaitu 71,95 (BPS Banten, 2019). Melalui pengelompokan survei UMKM berdasarkan kode KBLI, terlihat bahwa kode KBLI nomor 10 yaitu industri makanan (kuliner) di Kota Tangerang Selatan memiliki jumlah terbanyak sebesar 7.497 unit usaha (Dinas Koperasi dan UMKM Kota Tangerang Selatan, 2019).

Melihat besarnya potensi perkembangan UMKM sebagai salah satu faktor penggerak perekonomian, diharapkan penelitian ini dapat menggali lebih dalam mengenai pengaruh literasi keuangan terhadap inklusi keuangan beserta faktor penggeraknya, yaitu knowledge, skills, attitude dan behavior dengan menggunakan social capital sebagai variabel mediasi untuk mengukur pengaruh positifnya terhadap inklusi keuangan para pelaku usaha UMKM dengan kode KBLI di bidang usaha kuliner di wilayah Kota Tangerang Selatan di Provinsi Banten.

\section{TINJAUAN PUSTAKA}

\subsection{Financial Literacy}

Di dalam SNLKI (2017), OECD (The Organisation for Economic Co-Operation and Development) sebagai organisasi terkemuka di dalam penelitian literasi keuangan, menunjukkan bahwa literasi keuangan didefinisikan sebagai suatu proses, di mana konsumen keuangan atau investor mengembangkan pemahaman mereka mengenai layanan keuangan dan produk, konsep, dan risiko, dimana setiap informasi yang ada bertujuan untuk membantu mengasah keterampilan dan pengambilan keputusan mereka, mengetahui di mana untuk mencari bantuan dan meningkatkan kesejahteraan mereka. Menurut OJK di dalam POJK tahun 2016 literasi Keuangan adalah pengetahuan, keterampilan, dan keyakinan, yang mempengaruhi sikap dan perilaku untuk meningkatkan kualitas pengambilan keputusan dan pengelolaan keuangan dalam rangka mencapai kesejahteraan.

Pada penelitian yang dilakukan oleh Rodrigues et al. (2019), INFE atau International Network on Financial Education (2011) memandang literasi keuangan sebagai kombinasi dari awareness, attitude, knowledge, skills, dan behavior yang diperlukan untuk membuat keputusan keuangan yang sehat dan akhirnya mencapai 
kesejahteraan finansial individu. Sehingga terdapat dimensi dari literasi keuangan yang terdiri dari:

\subsubsection{Knowledge}

Orang yang melek finansial akan memiliki pengetahuan dasar tentang konsepkonsep utama keuangan (Atkinson \& Messy, 2012). Pada penelitian yang dilakukan oleh Bongomin et al. (2017) terdapat sebuah penelitian oleh Carpena et al. (2011) mengenai dampak literasi keuangan pada dimensi khususnya yaitu pengetahuan atau knowledge dimana ditemukan bahwa literasi keuangan meningkatkan tingkat kesadaran individu atas pengambilan keputusan dan sikap mereka secara finansial secara signifikan terhadap keputusan keuangan mereka. Literasi keuangan membuat peningkatan besar yang signifikan secara statistik atas kesadaran individu dalam memilih produk dan layanan keuangan yang tersedia untuk mereka.

\subsubsection{Skills}

Literasi keuangan adalah skills atau keterampilan untuk membuat keputusan yang diinformasikan dengan baik mengenai penerapan dan pengelolaan investasi keuangan dan diversifikasi risiko portofolio. Literasi keuangan juga dapat dianggap sebagai pemahaman konsep ekonomi dan moneter yang mendasar bersama dengan skills atau keterampilan untuk menggunakan pemahaman dan informasi, serta untuk menangani sumber daya keuangan secara efektif dan efisien (Lusardi \& Mitchell, 2014). Cole et al. (2011) pada penelitian yang dilakukan oleh Bongomin et al. (2017) mengungkapkan bahwa terdapat program literasi keuangan di Indonesia yang dirancang untuk memberikan pengajaran kepada masyarakat yang tidak memiliki rekening bank di dalam rumah tangga mereka tentang pentingnya rekening tabungan dengan demikian terlihat sedikit peningkatan dalam pembukaan rekening tabungan di antara mereka yang rendah tingkat literasi keuangannya. Dimana juga membantu mereka mengembangkan keterampilan atau skills untuk membandingkan dan memilih produk terbaik sesuai dengan kebutuhan mereka, dan juga memberdayakan mereka untuk menggunakan hak dan tanggung jawab mereka sesuai dengan perlindungan konsumen.

\subsubsection{Attitude}

Attitude dianggap sebagai elemen penting dari literasi keuangan. Jika orang memiliki sikap yang tidak suka menabung untuk masa depan mereka, maka, dapat dikatakan bahwa mereka tidak memiliki perilaku seperti itu. Demikian pula jika mereka lebih memprioritaskan keinginan jangka pendek, maka mereka tidak mungkin menyediakan tabungan darurat atau membuat rencana keuangan jangka panjang (Atkinson \& Messy, 2012). Pada penelitian yang dilakukan oleh Garg dan Singh (2018), Ajzen (1991) menyatakan financial attitude sebagai pra-disposisi untuk berperilaku dengan cara tertentu yang dibentuk oleh beberapa keyakinan individu secara ekonomi dan non-ekonomi pada bentuk tingkah laku tertentu.

\subsubsection{Behavior}

Cara seseorang berperilaku akan memiliki dampak signifikan pada kesejahteraan finansial mereka (Atkinson \& Messy, 2012). Pada penelitian yang dilakukan oleh Garg dan Singh (2018), OECD (2013) mengatakan cara seseorang berperilaku akan secara signifikan mempengaruhi kesejahteraan keuangannya. Oleh karena itu, penting untuk menangkap bukti dimensi behavior dalam literasi keuangan. Pada jurnal Bongomin et al. (2017), Holzmann (2010) mengungkapkan, perilaku financial atau financial behavior yang efektif di antara rumah tangga miskin di negara-negara berkembang ditunjukkan dengan kemampuan mereka dalam menyusun anggaran, perencanaan, dan menabung untuk hari tua serta mempromosikan penggunaan layanan keuangan. 


\subsection{Social capital}

Pada penelitian yang dilakukan oleh Lu \& Peng (2019), Putnam et al. (1993) mengatakan Social capital dapat di definisikan sebagai "fitur dari organisasi sosial, seperti kepercayaan, norma dan relasi, dimana dapat meningkatkan efisiensi dari sebuah lingkungan sosial dengan memfasilitasi koordinasi di antara setiap perilaku dari orangorang di dalam lingkungan sosial tersebut. Social capital banyak digunakan dalam penelitian yang berkaitan dengan hubungan di dalam masyarakat. Social capital dilakukan untuk mengumpulkan sumber daya yang dikumpulkan dan dibuatkan dalam hubungan sehari-hari dan interaksi dengan antar individu dan keluarga (Aldrich \& Meyer, 2014).

\subsection{Inklusi Keuangan}

Inklusi keuangan adalah ketersediaan akses pada berbagai lembaga, produk dan layanan jasa keuangan sesuai dengan kebutuhan dan kemampuan masyarakat dalam rangka meningkatkan kesejahteraan masyarakat (OJK, POJK, 2016). Inklusi keuangan dikenal sebagai proses yang menandai peningkatan kuantitas, kualitas, dan efisiensi lembaga keuangan, yang. dimana dapat membantu meningkatkan kehidupan, menumbuhkan peluang dan memperkuat perekonomian di suatu negara, serta peningkatan investasi produktif dalam bisnis lokal (Babajide, Adegboye, \& Omankhanlen, 2015). Inklusi keuangan menggambarkan bagaimana anggota dewasa masyarakat diberikan akses ke berbagai layanan keuangan yang tepat, yang dirancang berdasarkan kebutuhan mereka dan disediakan dengan biaya yang terjangkau (Le, Chuc, \& Hesary, 2019).

Pada SNKLI (Strategi Nasional Keuangan Literasi Indonesia) tahun 2017 oleh OJK, Center for Financial inclusion (2016) menjelaskan, inklusi keuangan sebagai akses terhadap produk keuangan yang sesuai untuk seorang individu masyarakat yang di dalamnya termasuk kredit, tabungan, asuransi, dan pembayaran, dengan tersedianya akses yang berkualitas seperti kenyamanan, keterjangkauan, kesesuaian serta dengan memperhatikan perlindungan konsumen, dan ketersediaan yang disediakan kepada semua orang (konsumen).

Di dalam SNKLI (2017) juga dijelaskan bahwa terdapat empat unsur dasar di dalam inklusi keuangan, yaitu : akses (berupa infrastruktur yang disediakan oleh lembaga keuangan agar masyarakat dapat menjangkau dan menggunakan produk serta layanan jasa keuangan dengan baik); ketersediaan produk dan layanan jasa keuangan; penggunaan produk dan layanan jasa keuangan serta kualitas produk atau jasa yang disediakan oleh lembaga keuangan memberikan nilai manfaat yang sebesar-besarnya untuk masyarakat.

Dari penjelasan diatas, maka dibangunlah sebuah rerangka konseptual penelitian seperti dibawah ini:

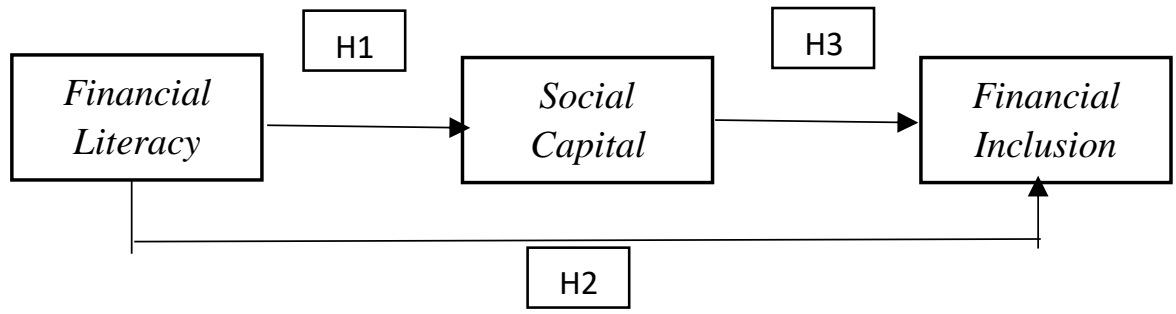

Sumber : Hasil Analisis Peneliti (2019)

Gambar 1. Rerangka Konseptual Penelitian 


\subsubsection{Pengaruh Financial literacy Terhadap Social capital}

Pada penelitian yang dilakukan oleh Chung \& Park (2014) ditemukan bahwa terdapat pengaruh dalam jaringan sosial yang memiliki kekuatan pada pendidikan keuangan dengan literasi keuangan yang mereka miliki. Dikutip dari OECD (2013), pada penelitian yang dilakukan oleh Ali, Anderson, McRae, \& Ramsay (2016) dikatakan bahwa literasi keuangan individu akan mempengaruhi orang-orang disekitarnya baik kenalan, teman dekat maupun keluarga (social capital). Pengetahuan keuangan yang dimiliki oleh individu tersebut akan dapat meningkatkan pula pemahaman mengenai uang, masalah keuangan, hak-hak konsumen, dan kesadaran mereka akan resiko-resiko yang muncul tentang dunia keuangan serta akan mempengaruhi tingkat pengambilan keputusan oleh orang-orang di dalam kelompoknya. Anggota kelompok akan lebih mempercayai informasi-informasi yang diberikan oleh orang terdekat mereka yang berada di dalam lingkungan kelompok yang sama. Berdasarkan pemaparan tersebut, maka disusunlah hipotesis sebagai berikut:

\section{H1: Financial literacy memiliki pengaruh terhadap social capital}

\subsubsection{Pengaruh Financial literacy Terhadap Financial inclusion}

Di dalam penelitiannya Mindra \& Moya (2017) mengemukakan bahwa financial literacy memiliki pengaruh yang positif terhadap financial inclusion dengan hasil model yang menunjukkan bahwa perubahan positif dalam tingkat keterampilan, pengetahuan dan pemahaman serta konsep-konsep keuangan dasar mengenai keuangan layanan dan dikaitkan dengan peningkatan inklusi keuangan dalam hal akses, penggunaan, dan kualitas di antara individu. Di dalam penelitian Grohmann A., Kluhs T. dan Menkhoff L. (2017) menunjukkan hasil bahwa peningkatan literasi keuangan dalam suatu populasi akan meningkatkan kepemilikan akun, dan akan memberikan pengaruh terbesar di negara-negara dengan tingkat pemahaman finansial yang rendah. Semakin banyak informasi keuangan yang mereka dapatkan, akan semakin tinggi pula pengetahuan keuangan yang mereka miliki, yang akan dijadikan dasar bagi mereka untuk mengambil keputusan. Dari penjelasan tersebut, maka dibentuklah hipotesis sebagai berikut:

H2 : Financial literacy memiliki pengaruh terhadap financial inclusion

\subsubsection{Social Capital Sebagai Mediator Variabel Dari Hubungan Financial Literacy Terhadap Financial Inclusion}

Dalam literasi keuangan, dimensi dari social capital tidak boleh diabaikan (Balatti, 2007). Bank Dunia (2010) pada penelitian yang dilakukan oleh Bongomin et al. (2018) juga menegaskan bahwa social capital dapat meningkatkan fungsi pasar pada tingkat ekonomi. Bongomin et al., (2017) menemukan pengaruh mediasi social capital terhadap hubungan dari financial literacy terhadap financial inclusion pada masyarakat di daerah Uganda. Serta adanya pengaruh yang signifikan dari network atau lingkungan sekitar terhadap hubungan dari financial literacy terhadap financial inclusion. Tingkat literasi keuangan individu serta pengaruh lingkungan kelompoknya, akan meningkatkan inklusi keuangan seseorang yang akan semakin meningkatkan interaksi mereka dengan lembaga keuangan. Berdasarkan hasil penelitian tersebut, dibuatlah sebuah hipotesis sebagai berikut:

\section{H3 : Social capital sebagai mediator variabel dari hubungan financial literacy terhadap financial inclusion}




\section{METODOLOGI DAN ANALISA DATA}

\subsection{Metodologi}

Populasi dalam penelitian ini adalah seluruh UMKM berkode kuliner di Kota Tangerang Selatan dengan jumlah 7.497 unit. Responden yang dipilih berdasarkan teknik stratified random sampling dari jumlah UMKM kuliner yang berada di tiap kecamatan dan sudah pernah berhubungan dengan lembaga keuangan. Jumlah sampel yang diambil adalah 150 dengan memperhitungkan adanya 30 indikator yang digunakan dalam penelitian ini. Metode yang dilakukan adalah dengan mendatangi langsung responden dan mendampingi responden saat mereka menjawab pertanyaan-pertanyaan penelitian yang terdapat di dalam kuesioner. Hasil data tersebut selanjutnya akan dianalisa dengan menggunakan Structural Equation Method (SEM).

\subsection{Analisa Data}

Hasil analisa deskriptif menunjukkan bahwa mayoritas responden telah memiliki unit usaha lebih dari 5 tahun (48\%). Hal ini menunjukkan bahwa mayoritas UMKM tersebut dapat bertahan cukup lama dalam menjalankan usahanya. $46 \%$ dari profil responden adalah pemilik yang sekaligus terlibat dalam kegiatan operasional bisnisnya. Sedangkan sisanya adalah supervisor dan penjaga toko yang sengaja direkrut oleh pemilik o untuk membantu usahanya. Para pemilik usaha ini memiliki pemahaman yang cukup mengenai lembaga keuangan serta sudah pernah melakukan penyimpanan dan peminjaman melalui lembaga keuangan secara manual maupun digital. Sedangkan berdasarkan lokasi domisili menunjukkan bahwa sebagian besar usaha UMKM kuliner di kota Tangerang Selatan berada di kecamatan Serpong dan Serpong Utara, yang memang menjadi pusat berdirinya banyak pabrik-pabrik industri.

Analisa hasil penelitian ini menggunakan metode SEM (Structural Equation Model) dengan software Amos versi 24.0 untuk melakukan uji validitas, realibilitas, hingga uji hipotesis penelitian. Hasil uji validitas terhadap keseluruhan variabel dapat dilihat pada tabel berikut:

Tabel 1. Tabel Uji Validitas Main Test

\begin{tabular}{|c|c|c|c|c|}
\hline No & Variabel & Indikator & $\begin{array}{c}\text { Standardized Loading Factors (SLF) } \\
\qquad 0,50\end{array}$ & Keterangan \\
\hline \multirow{15}{*}{1} & \multirow{15}{*}{$\begin{array}{l}\text { Financial } \\
\text { literacy }\end{array}$} & KL1 & 0,902 & Valid \\
\hline & & KL2 & 0,703 & Valid \\
\hline & & KL3 & 0,866 & Valid \\
\hline & & SK1 & 0,886 & Valid \\
\hline & & SK2 & 0,861 & Valid \\
\hline & & SK3 & 0,842 & Valid \\
\hline & & SK4 & 0,886 & Valid \\
\hline & & AT1 & 0,840 & Valid \\
\hline & & AT2 & 0,851 & Valid \\
\hline & & AT3 & 0,914 & Valid \\
\hline & & AT4 & 0,873 & Valid \\
\hline & & BH1 & 0,864 & Valid \\
\hline & & $\mathrm{BH} 2$ & 0,851 & Valid \\
\hline & & $\mathrm{BH} 3$ & 0,822 & Valid \\
\hline & & $\mathrm{BH} 4$ & 0,843 & Valid \\
\hline 2 & Social capital & SC1 & 0,736 & Valid \\
\hline
\end{tabular}




\begin{tabular}{|c|c|c|c|c|}
\hline No & Variabel & Indikator & $\begin{array}{c}\text { Standardized Loading Factors (SLF) } \\
\geq 0,50\end{array}$ & Keterangan \\
\hline & & $\mathrm{SC} 2$ & 0,714 & Valid \\
\hline & & SC3 & 0,827 & Valid \\
\hline & & $\mathrm{SC} 4$ & 0,685 & Valid \\
\hline & & SC5 & 0,713 & Valid \\
\hline \multirow{8}{*}{3} & \multirow{8}{*}{$\begin{array}{l}\text { Financial } \\
\text { inclusion }\end{array}$} & IK1 & 0,786 & Valid \\
\hline & & IK2 & 0,713 & Valid \\
\hline & & IK3 & 0,774 & Valid \\
\hline & & IK4 & 0,794 & Valid \\
\hline & & IK5 & 0,789 & Valid \\
\hline & & IK6 & 0,769 & Valid \\
\hline & & IK7 & 0,804 & Valid \\
\hline & & IK8 & 0,751 & Valid \\
\hline
\end{tabular}

Sumber : Hasil Pengolahan Data Primer (2019)

Hasil uji validitas untuk keseluruhan pengukuran dari variabel telah menunjukkan angka yang valid, dimana semua variabel memiliki angka standardized loading factor (SLF) di atas 0,50. Maka dapat disimpulkan bahwa seluruh pengukuran penelitian ini valid dan dapat mengukur sebuah variabel. Dari tabel validitas di atas dapat dilihat untuk variabel financial literacy pada dimensi knowledge dengan indikator KL2, variabel social capital pada indikator SC4, dan variabel financial inclusion pada indikator IK2 memiliki nilai validitas terendah di antara indikator lainnya.

Sedangkan hasil uji reliabilitas untuk pengujian semua variabel di dalam penelitian ini dapat ditunjukkan pada tabel 2 di bawah ini :

Tabel 2. Tabel Uji Reliabilitas

\begin{tabular}{|c|c|c|c|c|c|}
\hline No & Variabel & Indikator & $\mathrm{AVE} \geq \mathbf{0 , 5 0}$ & $\mathrm{CR} \geq 0, \mathbf{0 0}$ & Keterangan \\
\hline \multirow{15}{*}{1} & \multirow{15}{*}{$\begin{array}{l}\text { Financial } \\
\text { literacy }\end{array}$} & KL1 & \multirow{3}{*}{0,686} & \multirow{3}{*}{0,866} & \multirow{3}{*}{ Reliabel } \\
\hline & & KL2 & & & \\
\hline & & KL3 & & & \\
\hline & & SK1 & \multirow{4}{*}{0,755} & \multirow{4}{*}{0,925} & \multirow{4}{*}{ Reliabel } \\
\hline & & SK2 & & & \\
\hline & & SK3 & & & \\
\hline & & SK4 & & & \\
\hline & & AT1 & \multirow{4}{*}{0,757} & \multirow{4}{*}{0,926} & \multirow{4}{*}{ Reliabel } \\
\hline & & AT2 & & & \\
\hline & & AT3 & & & \\
\hline & & AT4 & & & \\
\hline & & $\mathrm{BH} 1$ & \multirow{4}{*}{0,714} & \multirow{4}{*}{0,909} & \multirow{4}{*}{ Reliabel } \\
\hline & & $\mathrm{BH} 2$ & & & \\
\hline & & $\mathrm{BH} 3$ & & & \\
\hline & & $\mathrm{BH} 4$ & & & \\
\hline \multirow{3}{*}{2} & \multirow{3}{*}{$\begin{array}{l}\text { Social } \\
\text { capital }\end{array}$} & SC1 & \multirow{3}{*}{0,543} & \multirow{3}{*}{0,855} & \multirow{3}{*}{ Reliabel } \\
\hline & & $\mathrm{SC} 2$ & & & \\
\hline & & SC3 & & & \\
\hline
\end{tabular}




\begin{tabular}{|c|c|c|c|c|c|}
\hline No & Variabel & Indikator & $\mathrm{AVE} \geq \mathbf{0 , 5 0}$ & $C R \geq 0,70$ & Keterangan \\
\hline & & $\mathrm{SC} 4$ & & & \\
\hline & & SC5 & & & \\
\hline \multirow{8}{*}{3} & \multirow{8}{*}{$\begin{array}{l}\text { Financial } \\
\text { inclusion }\end{array}$} & IK1 & \multirow{8}{*}{0,597} & \multirow{8}{*}{0,922} & \multirow{8}{*}{ Reliabel } \\
\hline & & IK2 & & & \\
\hline & & IK3 & & & \\
\hline & & IK4 & & & \\
\hline & & IK5 & & & \\
\hline & & IK6 & & & \\
\hline & & IK7 & & & \\
\hline & & IK8 & & & \\
\hline
\end{tabular}

Sumber : Hasil Pengolahan Data Primer (2019)

Tabel 2 tersebut menunjukkan bahwa untuk uji reliabilitas dengan syarat AVE $\geq$ 0,50 dan nilai $C R \geq 0,70$, semua variabel di dalam penelitian ini sudah reliabel dengan memenuhi syarat yang ada. Dapat disimpulkan bahwa variabel-variabel yang digunakan di dalam penelitian ini cukup handal untuk pengukuran dan dapat dijadikan variabel kembali untuk penelitian yang lebih lanjut.

Sedangkan uji kecocokan model pada model struktural dilakukan dengan menggunakan goodness of fit. Analisis perhitungan dengan menggunakan gambar model struktural sebagai berikut :

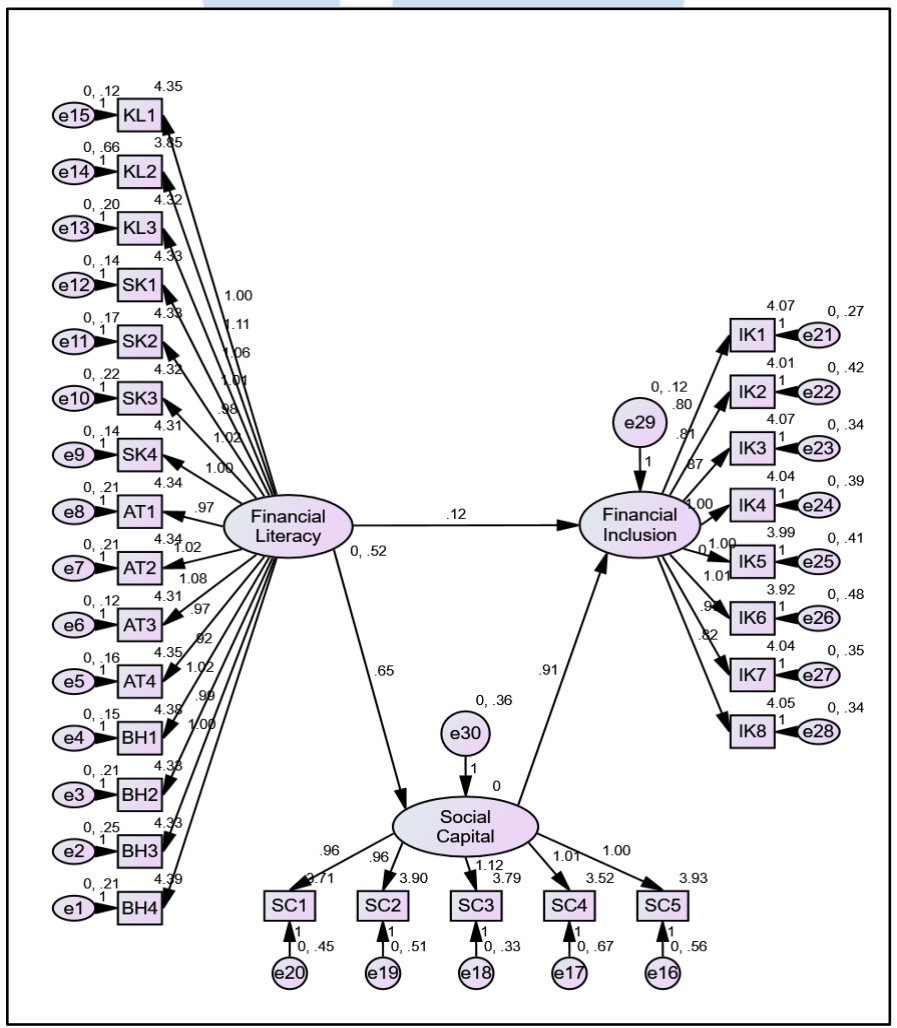

Sumber : Hasil Pengolahan Data Primer (2019)

Gambar 2. Model Struktural 
Dari gambar 2 tersebut, terlihatlah hasil uji dari model struktural untuk penelitian ini seperti yang dapat terlihat pada tabel 3 berikut ini:

Tabel 3 Hasil Measurement (Pengukuran) Struktural

\begin{tabular}{|c|c|c|c|c|}
\hline No & Variabel & Indikator & $\begin{array}{l}\text { Direct } \\
\text { Effect }\end{array}$ & Keterangan \\
\hline \multirow{15}{*}{1} & \multirow{15}{*}{$\begin{array}{l}\text { Financial } \\
\text { literacy }\end{array}$} & KL1 & 0,998 & Berpengaruh positif \\
\hline & & KL2 & 1,106 & Berpengaruh positif \\
\hline & & KL3 & 1,064 & Berpengaruh positif \\
\hline & & SK1 & 1,006 & Berpengaruh positif \\
\hline & & SK2 & 0,978 & Berpengaruh positif \\
\hline & & SK3 & 1,017 & Berpengaruh positif \\
\hline & & SK4 & 1,000 & Berpengaruh positif \\
\hline & & AT1 & 0,973 & Berpengaruh positif \\
\hline & & AT2 & 1,023 & Berpengaruh positif \\
\hline & & AT3 & 1,083 & Berpengaruh positif \\
\hline & & AT4 & 0,974 & Berpengaruh positif \\
\hline & & BH1 & 0,921 & Berpengaruh positif \\
\hline & & $\mathrm{BH} 2$ & 1,020 & Berpengaruh positif \\
\hline & & $\mathrm{BH} 3$ & 0,987 & Berpengaruh positif \\
\hline & & $\mathrm{BH} 4$ & 1,000 & Berpengaruh positif \\
\hline \multirow{5}{*}{2} & \multirow{5}{*}{$\begin{array}{l}\text { Social } \\
\text { capital }\end{array}$} & SC1 & 0,958 & Berpengaruh positif \\
\hline & & $\mathrm{SC} 2$ & 0,956 & Berpengaruh positif \\
\hline & & SC3 & 1,122 & Berpengaruh positif \\
\hline & & SC4 & 1,013 & Berpengaruh positif \\
\hline & & SC5 & 1,000 & Berpengaruh positif \\
\hline \multirow{8}{*}{3} & \multirow{8}{*}{$\begin{array}{l}\text { Financial } \\
\text { inclusion }\end{array}$} & IK1 & 0,816 & Berpengaruh positif \\
\hline & & IK2 & 0,974 & Berpengaruh positif \\
\hline & & IK3 & 1,014 & Berpengaruh positif \\
\hline & & IK4 & 0,997 & Berpengaruh positif \\
\hline & & IK5 & 1,000 & Berpengaruh positif \\
\hline & & IK6 & 0,873 & Berpengaruh positif \\
\hline & & IK7 & 0,807 & Berpengaruh positif \\
\hline & & IK8 & 0,799 & Berpengaruh positif \\
\hline
\end{tabular}

Sumber : Hasil Pengolahan Data Primer (2019)

Tabel 3 tersebut merupakan tabel pengukuran dari setiap indikator penelitian yang digunakan untuk mengukur dan merefleksikan variabel-variabel yang digunakan di dalam penelitian ini. Dari variabel financial literacy didapatkan indikator terkecil adalah indikator BH1 dengan nilai 0,921 dan nilai indikator terbesar pada indikator KL2 dengan nilai 1,106. Pada variabel social capital indikator dengan nilai terkecil diperoleh pada indikator SC2 dengan nilai 0,956 dan indikator terbesar berada pada indikator SC3 dengan nilai 1,122. Variabel financial inclusion memiliki indikator dengan nilai terendah yaitu indikator IK8 dengan angka 0,799 dan indikator dengan nilai tertinggi pada IK3 
dengan angka 1,014. Sedangkan hasil analisis terhadap kecocokan model structural dapat dilihat di tabel 4.

Tabel 4 Hasil Analisis Kecocokan Seluruh Model Struktural

\begin{tabular}{|c|c|c|c|}
\hline $\begin{array}{c}\text { Ukuran Goodness of Fit } \\
\text { (GOF) }\end{array}$ & Kecocokan yang Bisa Diterima & $\begin{array}{c}\text { Hasil } \\
\text { Estimasi }\end{array}$ & $\begin{array}{c}\text { Kriteria } \\
\text { Uji }\end{array}$ \\
\hline \multicolumn{4}{|c|}{ Absolute Fit Measure } \\
\hline Statistic Chi-Square $\left(\mathrm{X}^{2}\right)$ & Nilai yang kecil & 632,367 & $\begin{array}{l}\text { Good } \\
\text { Fit }\end{array}$ \\
\hline \multirow{3}{*}{$\begin{array}{l}\text { Root Mean Square Error } \\
\text { of Approximation } \\
\text { (RMSEA) }\end{array}$} & RMSEA $\leq 0.08$ & \multirow{3}{*}{0,074} & \multirow{3}{*}{$\begin{array}{l}\text { Good } \\
\text { Fit }\end{array}$} \\
\hline & $0.80 \leq \mathrm{RMSEA} \leq 0.10$ & & \\
\hline & RMSEA $\geq 0.10$ & & \\
\hline
\end{tabular}

Sumber : Hasil Pengolahan Data Primer (2019)

\begin{tabular}{|c|c|c|c|}
\hline $\begin{array}{c}\text { Ukuran Goodness of Fit } \\
\text { (GOF) }\end{array}$ & $\begin{array}{c}\text { Tingkat Kecocokan yang Bisa } \\
\text { Diterima }\end{array}$ & $\begin{array}{c}\text { Hasil } \\
\text { Estimasi }\end{array}$ & $\begin{array}{c}\text { Kriteria } \\
\text { Uji }\end{array}$ \\
\hline \multicolumn{4}{|c|}{ Incremental Fit Measure } \\
\hline \multirow{4}{*}{$\begin{array}{l}\text { Tucker-Lewis Index atau } \\
\text { Non-Normed Fit Index } \\
\text { (TLI atau NNFI) }\end{array}$} & $\mathrm{NNFI} \geq 0.90$ & \multirow{4}{*}{0,921} & \multirow{4}{*}{$\begin{array}{c}\text { Good } \\
\text { Fit }\end{array}$} \\
\hline & $0.80 \leq \mathrm{NNFI} \leq 0.90$ & & \\
\hline & $\mathrm{NNFI} \leq 0.80$ & & \\
\hline & $\mathrm{NFI} \leq 0.80$ & & \\
\hline \multirow[t]{3}{*}{ Incremental Fit Index (IFI) } & IFI $\geq 0.90$ & \multirow{3}{*}{0,928} & \multirow{3}{*}{$\begin{array}{c}\text { Good } \\
\text { Fit }\end{array}$} \\
\hline & $0.80 \leq \mathrm{IFI} \leq 0.90$ & & \\
\hline & $\mathrm{IFI} \leq 0.80$ & & \\
\hline \multirow{3}{*}{$\begin{array}{l}\text { Comperative Fit Index } \\
(\mathrm{CFI})\end{array}$} & $\mathrm{CFI} \geq 0.90$ & \multirow{3}{*}{0,927} & \multirow{3}{*}{$\begin{array}{c}\text { Good } \\
\text { Fit }\end{array}$} \\
\hline & $0.80 \leq \mathrm{CFI} \leq 0.90$ & & \\
\hline & $\mathrm{CFI} \leq 0.80$ & & \\
\hline
\end{tabular}

Sumber : Hasil Pengolahan Data Primer (2019)

\begin{tabular}{|l|c|c|c|}
\hline $\begin{array}{c}\text { Ukuran Goodness of Fit } \\
\text { (GOF) }\end{array}$ & $\begin{array}{c}\text { Tingkat Kecocokan yang Bisa } \\
\text { Diterima }\end{array}$ & $\begin{array}{c}\text { Hasil } \\
\text { Estimasi }\end{array}$ & $\begin{array}{c}\text { Kriteria } \\
\text { Uji }\end{array}$ \\
\hline \multicolumn{3}{|c|}{ Parsimonius Fit Measure } \\
\hline $\begin{array}{l}\text { Normed Chi-Square }\left(\mathrm{X}^{2}\right) \\
\text { Parsimonius Goodness Fit }\end{array}$ & CMIN/DF $<2$ & 1,817 & $\begin{array}{c}\text { Good } \\
\text { Fit }\end{array}$ \\
\hline
\end{tabular}

Sumber : Hasil Pengolahan Data Primer, 2019 
Berdasarkan dari hasil uji model struktural di atas, didapatkan model fit yang sudah baik karena nilai dari CMIN, PGFI, IFI, CFI, TLI, RMSEA dan Chi Square yang masuk ke dalam kategori good fit. Sehingga dari hasil ini model penelitian yang digunakan terkategorikan baik.

\section{HASIL PENELITIAN DAN DISKUSI}

Tujuan dari pengujian ini untuk menganalisa pengaruh dari financial literacy terhadap financial inclusion, financial literacy terhadap social capital, social capital terhadap financial inclusion, dan financial literacy terhadap financial inclusion dengan menggunakan mediasi social capital. Hasil dari pengujian hipotesis diuraikan di dalam tabel 5 berikut ini:

Tabel 5 Hasil Uji Hipotesis

\begin{tabular}{lccc}
\hline No & Hipotesis & $\begin{array}{c}\text { Std. } \\
\text { Coef. }\end{array}$ & $p$-value
\end{tabular}

\begin{tabular}{llccc}
\hline H1 $\begin{array}{l}\text { Financial literacy berpengaruh terhadap } \\
\text { financial inclusion pada UMKM di Kota } \\
\text { Tangerang Selatan }\end{array}$ & 0,103 & 0,137 & $\begin{array}{c}\text { Hipotesis 1 } \\
\text { ditolak }\end{array}$ \\
$\mathbf{H 2}$ & $\begin{array}{l}\text { Financial literacy berpengaruh terhadap } \\
\text { social capital pada UMKM di Kota } \\
\text { Tangerang Selatan }\end{array}$ & 0,617 & 0,000 & $\begin{array}{c}\text { Hipotesis 2 } \\
\text { diterima }\end{array}$ \\
$\mathbf{H 3} \begin{array}{l}\text { Social capital sebagai mediator variabel } \\
\text { dari hubungan financial literacy } \\
\text { terhadap financial inclusion dari UMKM } \\
\text { di Kota Tangerang Selatan }\end{array}$ & 0,622 & 0,000 & $\begin{array}{c}\text { Hipotesis 3 } \\
\text { diterima }\end{array}$ \\
\end{tabular}

Sumber : Hasil Pengolahan Data Primer (2019)

\subsection{Intepretasi Hasil}

\section{Hasil Uji Pengaruh Financial literacy terhadap Financial inclusion}

Hasil uji hipotesis dari penelitian ini menunjukkan bahwa Financial literacy tidak berpengaruh positif terhadap Financial inclusion. Hal ini berlawanan dengan penemuan yang ditunjukkan oleh Grohmann A., Kluhs T. dan Menkhoff L. (2017) yang menunjukkan hasil bahwa peningkatan literasi keuangan dalam suatu populasi akan meningkatkan kepemilikan akun, dan akan memberikan pengaruh terbesar di negaranegara dengan tingkat pemahaman finansial yang rendah. Hal ini dikarenakan walaupun pelaku UMKM di Kota Tangerang Selatan memiliki pengetahuan tetapi mereka lebih percaya terhadap informasi dari orang-orang disekitarnya.

\section{Hasil Uji Pengaruh Financial literacy terhadap Social capital}

Hasil uji hipotesis dari penelitian ini menujukkan bahwa financial literacy berpengaruh positif terhadap social capital. Hal ini karena frekuensi jawaban yang menunjukkan sikap yang baik dan positif dari literasi keuangan dan mempengaruhi 
lingkungan sosialnya. Kelompok yg punya karakteristik atau behavior yg sama Didukung oleh temuan dari Cohen dan Nelson (2011) dengan hasil penelitian yang menunjukkan rumah tangga miskin yang berada di dalam suatu jaringan (networks) tertentu dapat meningkatkan pengetahuan dan keterampilan keuangannya, serta dapat mengambil keputusan keuangan yang lebih bijak. Dijelaskan juga dalam jurnal Ali, Anderson, McRae, \& Ramsay (2016) bahwa literasi keuangan individu dipengaruhi oleh tingkat social capital yaitu mengenai pengetahuan yang dapat diserap dan dimiliki oleh kaum muda mengenai uang, masalah keuangan, hak-hak konsumen mereka, dan kesadaran mereka akan bahaya tentang dunia keuangan.

\section{Hasil Uji Social capital sebagai mediator variabel di dalam hubungan Financial Literacy terhadap Financial inclusion}

Hubungan mediasi social capital pada hubungan financial literacy terhadap financial inclusion dengan tingkat signifikan 0,000 yang diuji oleh peneliti melalui Sobel Test dengan hasil uji sebagai berikut :

Tabel 6. Hasil Uji Sobel Test

\begin{tabular}{|c|c|c|}
\hline No & Nilai Estimated & Standard Error \\
\hline 1 & 0,648 & 0,095 \\
\hline 2 & 0,908 & 0,121 \\
\hline & Sobel Test Statistic & 5,0475 \\
\hline Two-Tailed Probability & 0,000 \\
\hline
\end{tabular}

Sumber : Pengolahan Data Primer (2019)

Dari hasil uji sobel test tersebut terlihat bahwa terdapat mediasi secara signifikan untuk social capital di dalam hubungan financial literacy terhadap financial inclusion. Didukung oleh penelitian dari Bongomin et al., (2017) yang menemukan pengaruh mediasi social capital terhadap hubungan dari financial literacy terhadap financial inclusion pada masyarakat di daerah Uganda.

\section{Upaya Peningkatan Financial literacy terhadap Financial inclusion}

Berdasarkan hasil pengolahan data yang menunjukkan variabel financial literacy tidak berpengaruh terhadap variabel financial inclusion dapat disimpulkan bahwa financial literacy atau literasi keuangan dari UMKM di Kota Tangerang Selatan belum maksimal sehingga tidak mempengaruhi financial inclusion atau inklusi keuangan pada penelitian ini. Dari hasil penelitian ini terlihat bahwa terdapat kurangnya upaya yang dilakukan oleh lembaga keuangan dalam peningkatan edukasi untuk produk dan layanan keuangan yang lebih menyeluruh dan praktikal. Tujuan dari upaya peningkatan edukasi ini untuk membantu pelaku UMKM dalam mengaplikasikan secara langsung dasar pengetahuan atas produk dan jasa dalam kehidupan sehari-hari mereka serta memberikan mereka dasar pengetahuan perbandingan produk dan layanan keuangan dari berbagai jenis produk dan layanan yang ditawarkan. Disisi lain pemerintah juga perlu meningkatkan standar edukasi keuangan dari semenjak sekolah dasar sampai dengan pendidikan tertinggi. Pemerintah juga dapat memberikan materi-materi kepada masyarakat yang tidak berpendidikan atau kurang berpendidikan melalui media-media offline dan online. Dengan adanya sosialisasi dalam bentuk champaign yang diberikan oleh pemerintah akan membantu masyarakat untuk lebih memahami dan menambah 
pengetahuan mengenai resiko dan keuntungan dari produk dan jasa yang diberikan oleh lembaga keuangan.

\section{Upaya Peningkatan Financial literacy di dalam Social capital}

Terdapat cara yang dapat dilakukan oleh lembaga keuangan dengan lebih meningkatkan sosialisasi untuk pengetahuan dasar dari produk yang mereka tawarkan lebih baik. Seperti contoh untuk lembaga keuangan yang baru masuk di dunia keuangan yang memberikan akses lebih mudah untuk UMKM yaitu peer to peer lending dan crowdfunding. Edukasi lebih lanjut untuk produk dan nilai yang dapat mereka tawarkan kepada pemilik usaha dari UMKM, serta keuntungan yang mereka dapatkan dari meminjam uang dan mengembangkan usaha mereka dengan uang pinjaman. Dan yang terpenting bagaimana menghitung tingkat bunga kredit yang diberikan sehingga mereka dapat mengetahui lebih dalam simulasi kredit dan seberapa besar keuntungan dan beban yang mereka dapatkan dari peminjaman uang akan mereka ambil. Bagi pemerintahan Kota Tangerang Selatan dapat lebih memberikan layanan edukasi untuk UMKM. Layanan yang dimaksud seperti seminar pendidikan literasi keuangan, layanan customer service untuk konsultasi mengenai pengetahuan seputar lembaga keuangan dan pengetahuan-pengetahuan dasar keuangan lainnya. Serta memberikan bantuan akses dan fasilitas kepada lembaga keuangan untuk lebih mudah masuk ke dalam lingkungan atau komunitas UMKM.

\section{Upaya Peningkatan Social capital di dalam hubungan Financial Literacy terhadap Financial inclusion}

Terdapat upaya-upaya yang dapat dilakukan oleh beberapa pihak terkait untuk menumbuhkan faktor ini seperti pemerintah harus menumbuhkan aspek trust atau percaya kepada masyarakat untuk lebih ketat dalam memperhatikan tindak kriminalitas atau tidak diberikan kembali hak dari seorang individu atas uang yang sudah dipinjam. Karena dengan peraturan dan pengawasan yang ketat akan membuat resiko peminjaman uang yang diberikan antar individu akan lebih berkurang dan menjamin pihak yang meminjamkan uang untuk uangnya dapat dikembalikan sesuai dengan peraturan yang berlaku. Pemerintah juga harus lebih memberdayakan koperasi dan asosiasi untuk bekerjasama dan menumbuhkan financial inclusion di dalam lingkungan sosial masingmasing daerah. Dengan memberikan sosialisasi dan materi melalui koperasi dan asosiasi dan terus mengembangkan fungsi dari kedua organisasi ini agar dapat membantu dalam mengembangkan masyarakat yang lebih inklusif terhadap keuangan. Lembaga keuangan dapat menjadikan suatu komunitas atau lingkungan di sekitar UMKM dengan diberikan lebih banyak edukasi dan peningkatan fasilitas untuk pemenuhan kebutuhan produk dan layanan keuangan dari lingkungan di sekitar target pasar. Menjadikan influencer dari suatu komunitas untuk ikut memberikan pengetahuan mengenai produk dan layanan keuangan yang sesuai dengan target pasar yang dituju. Serta terus menjalin kerjasama dengan lembaga keuangan lainnya di dalam ekosistem keuangan untuk menciptakan nilai-nilai baru seperti yang sudah dilakukan yaitu joint financing oleh bank dan lembaga keuangan digital. 


\section{KESIMPULAN}

Dari hasil pengambilan data yang diolah dan dianalisa, maka dapat disimpulkan bahwa penelitian ini menghasilkan beberapa temuan yaitu financial literacy tidak berpengaruh dengan financial inclusion pada UMKM di Kota Tangerang Selatan. Hal ini ditunjukkan dengan nilai standar keofisien yang positif tetapi nilai $p$-value yang lebih besar dari 0,05 yaitu 0,137. Dapat disimpulkan bahwa knowledge, skill, behavior, dan atttitude tidak memberikan pengaruh terhadap financial inclusion. Dengan demikian literasi keuangan tidak memberikan pengaruh pada inklusi keuangan dari UMKM di Kota Tangerang Selatan. Financial literacy berpengaruh terhadap social capital pada UMKM di Kota Tangerang Selatan. Dengan nilai standar koefisien sebesar 0,617 dan p-value sebesar 0,000. Dengan demikian literasi keuangan yang dimiliki oleh UMKM di Kota Tangerang Selatan akan dibagikan kepada lingkungan sosialnya. Social capital sebagai mediator variabel dari hubungan financial literacy terhadap financial inclusion dari UMKM di Kota Tangerang Selatan. Dengan nilai standar koefisien sebesar 0,622 dan pvalue 0,000. Dengan demikian social capital dapat membantu financial literacy dalam menciptakan inklusi keuangan yang lebih baik pada lingkungan UMKM di Kota Tangerang Selatan.

Peneliti menyarankan agar lembaga keuangan lebih aktif dalam memberikan edukasi untuk produk dan jasa yang ditawarkan dan menyesuaikan needs dari UMKM dari waktu ke waktu sehingga dapat mendorong mereka untuk lebih berkembang. Seperti perubahan pola hidup masyarakat yang lebih modern dengan mendigitalisasikan semua produk yang mereka miliki dan perubahan sistem peminjaman modal usaha yang lebih mudah dan efisien. Lembaga keuangan juga harus lebih menjangkau daerah-daerah yang terpencil atau tidak terlalu terjangkau oleh layanan keuangan. Karena masih ada beberapa tempat yang didapatkan kurang terjangkau oleh produk dan layanan yang ditawarkan lembaga keuangan terhadap pelaku UMKM. Keterbatasan media yang dimiliki oleh pelaku UMKM dalam mengakses produk dan jasa keuangan perlu untuk lebih dipertimbangkan seperti kurangnya sarana infrastruktur online untuk produk-produk online, kurangnya tingkat kapasitas dari pelaku UMKM untuk menjangkau produk atau layanan, dan kurangnya syarat-syarat untuk memenuhi persyaratan untuk akses pinjaman serta beberapa faktor lain yang ikut menjadi keterbatasan dari pelaku UMKM untuk mengakses produk dan layanan keuangan. Meningkatkan upaya joint financing yang dilakukan oleh lembaga keuangan bank dan lembaga keuangan lainnya seperti fintech. Strategi joint financing diatur di dalam peraturan OJK Nomor 35/POJK.05/2018, Tentang Penyelenggaraan Usaha Perusahaan Pembiayaan. Terus membangun ekosistem digital bersamaan dengan lembaga keuangan untuk pelaku UMKM agar dapat terus mengembangkan sayapnya melalui program edukasi pengembangan usaha yang bertujuan untuk memberikan produk dan layanan keuangan yang akan mendukung permodalan mereka dalam pengembangan usaha.

Peneliti menyarankan kepada pemerintah Kota Tangerang Selatan untuk lebih melibatkan fintech dalam meningkatkan inklusi keuangan pada UMKM Kota Tangerang Selatan. Dengan memberikan fasilitas yang mempermudah fintech dalam menggapai UMKM di Kota Tangerang Selatan seperti penyaluran jalur informasi, menyediakan forum yang mempertemukan pihak fintech dengan UMKM dan menyalurkan UMKM yang membutuhkan bantuan keuangan kepada fintech. Serta memberikan layanan konsultasi untuk menabung dan mendorong pinjaman modal usaha. Sehingga hasil dari tabungan dan pinjaman mereka dapat mereka gunakan sebagai modal ekspansi usaha mereka. 


\section{IMPLIKASI /KETERBATASAN DAN SARAN UNTUK PENELITIAN SELANJUTNYA}

Peneliti menyarankan untuk penelitian selanjutnya untuk menambah demografi dan variabel dalam penelitian selanjutnya. Demografi yang dapat ditambahkan pada penelitian adalah umur dan pendidikan terakhir. Peneliti menyarankan untuk mengimplikasikan penelitian selanjutnya lebih fokus kepada fintech, sehubungan dengan perkembangan teknologi digital dalam dunia keuangan di Indonesia dan munculnya startup fintech seperti peer to peer lending dan crowdfunding yang menargetkan UMKM sebagai konsumen utama mereka. Berdasarkan dengan nilai $\mathrm{R}^{2}$ sebesar $82,5 \%$ yang menandakan terdapat sebesar $17,5 \%$ faktor-faktor lain yang dapat mempengaruhi tingkat literasi keuangan terhadap inklusi keuangan. Sehingga peneliti menyarankan untuk menambah variabel financial education pada penelitian selanjutnya yang didukung oleh jurnal Cordero, Gil-Izquierdo, \& Pedraja-Chaparro (2019) yang menjelaskan bagaimana edukasi keuangan akan mempengaruhi literasi keuangan seorang individu. Karena faktor edukasi secara formal dan nonformal akan menciptakan individu dengan literasi yang tinggi sehingga dapat mengelola keuangan mereka lebih baik.

\section{ACKNOWLEDGEMENT}

Peneliti mengucapkan terima kasih yang sedalam-dalamnya kepada Bapak Dian Faqihdien Suzabar, S.T., M.Bus. (IT) sebagai Head Corporate Action Bank Mandiri Syariah yang telah memberikan masukan terhadap penelitian dan artikel ini.

\section{REFERENSI}

Aldrich, D. P., \& Meyer, M. A. (2014). Social Capital and Community Resilience. American Behavioral Scientist, 254-269.

Atkinson, A., \& Messy, F.-A. (2012). Measuring Financial Literacy : Results of the OECD/International Network on Financial Education (INFE) Pilot Study. OECD Working Papers on Finance, Insurance and Private Pensions.

Babajide, A. A., Adegboye, F. B., \& Omankhanlen, A. E. (2015). Financial Inclusion and Economic Growth in Nigeria. International Journal of Economics and Financial Issues.

Badan Perencana Pembangunan Nasional. (2019, Agustus 16). Lampiran Pidato Kenegaraan Presiden Republik Indonesia. Retrieved September 13, 2019, from bappenas.go.id: 2019/Lampid_2019.pdf

https://www.bappenas.go.id/files/lampid/lampid-

Balatti, J. (2007). Financial literacy and social networks - what's the connection? ALA National Conference. Cairns: James Cook University.

Bank Indonesia. (2019). Keuangan Inklusif di Indonesia. Retrieved November 20, 2019, from https://www.bi.go.id/id/perbankan/keuanganinklusif/Indonesia/Contents/Default. aspx

Blesia, J. U. (2017). Culture and Accounting Practices in Indonesia. Asian Journal of Economics, Business and Accounting.

Bongomin, G. O., Ntayi, J. M., Munene, J. C., \& Malinga, C. A. (2017). Financial intermediation and financial inclusion of poor households : Mediating role of social network in rural Uganda. Cogent Economics \& Finance. 
Bongomin, G. O., Ntayi, J. M., Munene, J. C., \& Malinga, C. A. (2017). Financial literacy in emerging economies. Managerial Finance, 1310-1331.

Bongomin, G. O., Ntayi, J. M., Munene, J. C., \& Malinga, C. A. (2018). Institutions and Financial Inclusion in Rural Uganda : the Mediating Role of Social Capital. Journal of African Business, 244-261.

Bongomin, G. O., Ntayi, J. M., Munene, J. C., \& Nabeta, I. N. (2015). Social Capital : Mediator of Financial Literacy and Financial Inclusion in Rural Uganda. Review of International Business and Strategy.

Bongomin, G. O., Ntayi, J. M., Munene, J. C., \& Nabeta, I. N. (2016). Financial Inclusion in Rural Uganda : Testing Interaction Effect of Financial Literacy and Networks. Journal of African Business, 106-128.

BPS. (2019, November 06). Industri Mikro dan Kecil. Retrieved November 07, 2019, from bps.go.id: https://bps.go.id/subject/170/industri-mikro-dankecil.html\#subjekViewTab3

BPS. (2019). Produk Domestik Bruto (Lapangan Usaha). Retrieved September 3, 2019, from bps.go.id: https://www.bps.go.id/subject/11/produk-domestik-bruto-lapangan-usaha-.html

BPS Banten. (2019). Provinsi Banten Dalam Angka. Badan Pusat Statistik Provisi Banten.

Chung, Y. H., \& Park, Y. K. (2014). The Effects of Financial Education and Networks on Business Students Financial Literacy. American Journal of Business Education.

Cordero, J. M., Gil-Izquierdo, M., \& Chaparro, F. P. (2019). Financial Education and Student Financial Literacy : A Cross-Country Analysis Using PISA 2012 Data. The Social Science Journal.

Garg, N., \& Singh, S. (2018). Financial Literacy Among Youth. International Journal of Social Economics, 176-186.

Ghahtarani, A., Majid, S., \& Mahdieh, R. (2019). The impact of social capital land social interaction on customers' purchase intention, considering knowledge sharing in social commerce context. Journal of Innovation \& Knowledge.

Ghozali, H. I., \& Ratmono, D. (2013). Analisis Multivariat dan Ekonometrika Teori, Konsep,dan Aplikasi dengan EViews 8. Semarang: Badan Penerbit Universitas Diponegoro Semarang.

Grohmann, A., Kluhs, T., \& Menkhoff, L. (2017). Does financial literacy improve financial inclusion? German Institute for Economic Research.

Hair Jr., J. F., Black, W. C., Babin, B. J., \& Anderson, R. E. (2014). Multivariate Data Analysis. Edinburgh: Pearson Education Limited.

Hausken, K. d. (1996). Hegemons, Leaders and Followers:A Game-Theoretic Approachto the Postwar Dynamicsof International Political Economy. MPIFG Discussion Paper.

Hofstede, H. G. (2001). Culture Consequences : Comparing Values, Behaviors, Institutions and Organizations Across Nations - Second Edition. California: Sage Publications.

Kementrian Keuangan. (2019). RAPBN 2019. Retrieved October 1, 2019, from kemenkeu.go.id: https://www.kemenkeu.go.id/single-page/rapbn-2019/

Le, T.-H., Chuc, A. T., \& Hesary, H. F. (2019). Financial inclusion and its impact on financial efficiency and sustainability: Empirical evidence from Asia. Borsa Istanbul Review. 
Lu, N., \& Peng, C. (2019). Community-Based Structural Social Capital and Depressive Symptoms of Older Urban Chinese Adults : The Mediating Role Cognitive Social Capital. Archives of Gerontology and Geriatrics, 74-80.

Lusardi, A., \& Mitchell, O. (2014). The economic importance of financial literacy : Theory and evidence. Journal of economy literacy, 5-44.

Maholtra, K. M. (2010). Marketing Research : An Applied Orientation, 6th Edition. New Jersey: Georgia Institute of Technology.

Mindra, R., \& M., M. (2017). Financial self-efficacy : a mediator in advancing financial inclusion. Equality, diversity and inclusion. An International Journal, 128-149.

Moarefi, A., \& Sweis, R. J. (2018, December). Publication Sobel test. Retrieved December 04, 2019, from Researchgate.net: https://www.researchgate.net/publication/329371676_Sobel_test/stats

OJK. (2014). Survei Baseline Portfolio Investasi UMKM Rumah Tangga : Upaya Meningkatkan Partisipasi Masyarakat Dalam Penggunaan Produk Lembaga Jasa Keuangan. Jakarta: OJK.

OJK. (2016). POJK. Retrieved Oktober 10, 2019, from ojk.go.id: https://www.ojk.go.id/id/kanal/edukasi-dan-perlindungan-

konsumen/regulasi/peraturan-ojk/Documents/Pages/POJK-tentang-PeningkatanLiterasi-dan-Inklusi-Keuangan-di-Sektor-Jasa-Keuangan-Bagi-Konsumen-danatau-masyarakat/SAL\%20-\%20POJK\%20Literasi\%20dan\%20Inkl

OJK. (2017). Strategi Nasional Literasi Keuangan Indonesia. Revisit 2017.

OJK. (2017, April 03). Undang-Undang Nomor 20 Tahun 2008 Tentang Usaha Mikro, Kecil, dan Menengah. Retrieved November 27, 2019, from ojk.go.id: https://www.ojk.go.id/sustainable-finance/id/peraturan/undang-

undang/Pages/Undang-Undang-Republik-Indonesia-Nomor-20-Tahun-2008-

Tentang-Usaha-Mikro,-Kecil,-dan-Menengah.aspx

OJK. (2019, Juni). Statistik Perbankan Indonesia. Volume 17.

Pusat Kebijakan Perdagangan Dalam Negeri Badan Pengkajian dan Pengembangan

Kebijakan Perdagangan Kementrian Perdagangan. (2013). Analisis Peran Lembaga Pembiayaan Dalam Pengembangan UMKM.

Rodrigues, L. F., Oliveira, A., Rodrigues, H., \& Costa, C. J. (2019). Assessing Consumer Literacy on Financial Complex Products. Journal of Behavioral and Experimental Finance.

Sensus UMKM. (2018). Data Sensus UMKM Kota Tangerang Selatan. Kota Tangerang Selatan: Dinas Koperasi dan UMKM.

Soetiono, K. S., \& Setiawan, C. (2018). Literasi dan Inklusi Keuangan Indonesia. Depok: Kharisma Putra Utama Offset.

Wijanto, S. H. (2008). Structural Equation Model. Graha Ilmu: Yogyakarta.

World Bank. (2018). The Little Data Book on Financial Inclusion. Washington DC: The World Bank Group.

Worldbank. (2019). Open Data. Retrieved September 8, 2019, from worldbank.org: https://data.worldbank.org/country/indonesia

Yay, M. (2016). The Mediation Analysis With The Sobel Test and The Percentile Bootstrap. Research World International Conference.

Zikmund, W. G., Babin, B. J., Carr, J. C., \& Griffin, M. (2013). Business Research Method. South-Western: Cengage Learning. 